\title{
Oscillatory zoned liddicoatite from Anjanabonoina, Madagascar: core- to-edge variation of trace element abundances by LA-ICP-MS
}

\author{
AARON J. LUSSIER ${ }^{1}$ AND FRANK C. HAWTHORNE ${ }^{2}$
}

${ }^{1}$ Canadian Museum of Nature, Mineral Sciences, Ottawa, Canada. alussier@nature.ca

${ }^{2}$ University of Manitoba, Dept. Geological Sciences,

Winnipeg, Canada. frank.hawthorne@umanitoba.ca

Crystals of liddicoatite, ideally $\mathrm{Ca}\left(\mathrm{Li}_{2} \mathrm{Al}\right) \mathrm{Al}_{6}\left(\mathrm{BO}_{3}\right)_{3}$ $\left(\mathrm{Si}_{6} \mathrm{O}_{18}\right)(\mathrm{OH})_{3} \mathrm{~F}$, showing prominent oscillatory colourzoning, are known only from the Anjanabonoina pegmatite of Madagascar. Lussier et al. (2011) and Lussier \& Hawthorne (2011), characterized variations in structure and composition across a single crystal, in which mm-scale zones are visually (and compositionally) observed as discontinuities in colour intensity (and element abundance), which exponentially decrease or increase toward the next zone. These investigations concluded that zoning results from element-selective feedback at the growth interface, not episodic changes in melt composition, with critical evidence being marked differences in major-element behaviour at simultaneously-growing pyramid and prism faces.

Modelling multi-element oscillatory behaviour in tourmaline (and other phases) requires better understanding of element-selectivity as a function of the growth face structure. Trace elements are sensitive indicators of site-specific incorporation preferences.

Here, continuous, core-to-edge, profiles of 32 traceelements, collected by LA-ICP-MS on the previously investigated crystal are discussed. Profiles fall into four groups. [1] Zoned, wherein oscillation behaviour mimics that of major elements (Ti, V, Zn, Nb, Sn, Ta, Pb, Bi, Th). [2] Flat/monotonic, wherein no oscillatory behaviour is observed (Be, $\mathrm{Cu}, \mathrm{Ga}, \mathrm{Sr}, \mathrm{W}$ ). [3] LREE, wherein oscillations profiles are inverted relative to those of major elements (La to $\mathrm{Nd}$ ).

[4] Where the prism sector only shows measurable abundance (Sc, Co, Y, Sb, Sm to Lu).

Correlations between trace-elements, major-elements and colour show trends in melt chemistry. Between pyramidal and prismatic faces, there are differences for nearly all investigated trace elements, as observed for major elements, and in accord with diffusion- and structure-dependent feedback mechanisms during growth. References: Lussier et al. (2011), Can. Min. 49: 63-88; Lussier \& Hawthorne (2011), Can. Min. 49 : 89-104. 